\title{
Integration of Government Services using Semantic Technologies
}

\author{
Ján Hreňo ${ }^{1}$, Peter Bednár $^{2}$, Karol Furdík $^{3}$ and Tomáš Sabol ${ }^{4}$ \\ Technical University of Košice, Faculty of Economics, Letná 9, 04200 Košice, Slovakia, ${ }^{1}$ jan.hreno@tuke.sk, \\ ${ }^{2}$ peter.bednar@tuke.sk, ${ }^{3}$ karol.furdik@intersoft.sk, ${ }^{4}$ tomas.sabol@tuke.sk
}

Received 15 July 2010; received in revised form 04 November 2010; accepted 22 December 2010

\begin{abstract}
The paper describes an approach to semantic interoperability of eGovernment services applied within the 027020 FP6 IST Access-eGov project. The goal of the project was to improve accessibility and connectivity of governmental services for citizens and businesses by means of creating integrated scenarios and providing guidance to users while following this scenario. The scenario helps the user to identify and fulfil any needed electronic or real governmental services in a selected life situation. The Access-eGov project has developed software tools enabling service integration using semantic technologies. In addition to that, a methodology providing guidance to the user-driven process of creating ontologies was developed. Sample ontologies were prepared for trial applications. The developed tools support browsing, discovery, and execution of government services according to a selected life event or goal. The project successfully developed and tested the proposed solutions. The software developed within the project is available as open source software.
\end{abstract}

Keywords: E-government, Semantic web services, Semantic interoperability, Ontology, Semantic annotation

Ján Hreňo Peter Bednár Karol Furdík Tomáš Sabol 


\section{Introduction}

Semantic interoperability, i.e. technical capability of interoperation of provided services, is nowadays considered to be a key challenge in several fields (eBusiness, eHealth, etc.), and in particular in the field of eGovernment. Interoperability was also recognised as a precondition for the implementation of European eGovernment services in the eEurope Action Plan [4] and was explicitly addressed as one of the four main challenges in the i2010 EU strategy [5]. This is important especially for integration and co-operation of existing services - employing solutions based on existing standards, open specifications and open interfaces [6].

One of the most promising approaches to interoperability is the employment of semantic technologies [1], [18]. Semantics provides the capability to model and represent knowledge within a given domain by means of explicit formalisation of key domain concepts, their attributes and relations, as well as workflow sequences and structures. Considering the heterogeneous and distributed nature of the eGovernment domain, semantics can be effectively used as a common background platform for describing processes and services provided by governmental institutions on various levels. The common platform then enables to integrate the services, make them interoperable and transparent for end users (citizens and-or businesses).

Intensive research in the application of semantics in the eGovernment field is being carried out, mostly focused on integration of back-offices, employing Service Oriented Architecture and Web Services enriched by a semantic description [1], [2], [9], [15], [20]. This direction of research is also documented by projects supported by the European Commission within the Information Society Technologies (IST) programme (Site 1). Most of the solutions apply semantic technologies to ease the system design by modelling the user's behaviour, to enable or enhance interoperability of services, to provide a platform for the creation of semantically described web services, etc. Provision of better and well-integrated public services to citizens and businesses can be recognised as a common goal of all these research efforts. In the following paragraphs, we will briefly mention some of the R\&D projects, which can be considered as examples of the existing solutions and approaches.

There is a wide range of approaches, proposals, frameworks, and projects in the area of semantic interoperability in the eGovernment domain, especially dealing with the creation and management of semantic web services. However, practical outcomes of the research in this area (see e.g. [18]) are somehow lagging behind original expectations. The lack of supporting methodology, specialised tools, and guidelines describing how to create and maintain formal semantic descriptions of the services in practical applications may be one of the reasons. Another reason may be a weak support for existing types of governmental services, and the necessity to dramatically change (reengineer) the way governmental services are being provided, e.g. by implementing them as semantically described web services.

One of the main advantages of the semantic enhancement of government services is the capability to formally describe meaning and context of the services, both traditional (i.e. "paper-based", face-to-face services) as well as electronic ones (provided as electronic forms or as web services), without the necessity to modify the services themselves. The Access-eGov project (Site 2), which was a R\&D project funded by the European Commission within the 6th Framework Programme (FP6), was targeting this issue by developing SW tools and a methodology enabling semantic interoperability of government services in practical applications. Access-eGov addressed one of the main objectives of the Action Plans eEurope and eEurope+ "Government on-line: electronic access to public services" by "bringing administrations closer to citizens and businesses through the use of Internet", while putting the user at the centre. The project consortium consisted of universities and IT companies (with expertise in knowledge management, semantic web technologies, business processes, administrations in need of user-friendly solutions providing information and e-services for complex life events), public administration and non-profit organizations (bringing into the project also requirements of citizens, including disadvantaged groups).

\section{Methodology and Tools, Access-eGov Approach}

The main objective of the Access-eGov project was to provide support for citizens and businesses in their life event situations and business episodes, respectively, with access to governmental services (either "traditional" or electronic ones) in an integrated manner. Following this objective, a user driven approach was applied, ensuring that the R\&D project results would serve users' needs. To this end, three pilot applications and one user test lab, each divided into two trials, were implemented and the trial evaluation strategy (measuring quality of information integration, information quality, process improvement and issues like usability of interfaces, security, trust etc.) was set up in order to get measurable feedback from the users.

Taking life events (business episodes in case of businesses) as an expression of user's needs is in correspondence with the life event approach [13] - an effective and frequently used method in the user-oriented eGovernment solutions. A life event is a situation in the life of a citizen (in case of a business episode - in a life cycle of the business organisation), which requires provision of government services and should be semantically described within the system. Life events are usually complex and can be decomposed into several mutually dependent sub-goals. Fulfilment of the sub-goals leads to the solution of the given situation. Each sub-goal can be resolved to (i.e. fulfilled 
by) a set of government services, that are provided either in a traditional way (requiring face-to-face communication and mostly paper-based) or in an electronic way (available on-line via web service interfaces or web forms).

Sub-goals can be conditioned, organised in workflow structures using IF-THEN-ELSE constructs, cycles, and dependencies on outputs of other services - according to the specific case of the citizen or the organisation. During the execution, the list of sub-goals for a life event is customised (e.g. by information provided by the user to specify his/her case) and then dynamically evaluated [15]. Services, which resolve sub-goals, may require some additional inputs provided by other services, so sub-goals can be further decomposed into sub-sub-goals and so on. During the service resolution process, the Access e-Gov system dynamically creates a user scenario by evaluating conditions of sub-goals, and then navigates the user to relevant services to fulfil the goals and solve the life event situation.

Ontologies, as powerful knowledge representation formalism for modelling real-world concepts, were chosen as a basic mechanism for semantic modelling and annotation of life events, goals, sub-goals, services, and other specific concepts from the public administration (PA) domain. This approach allows the integration of existing (and prospective future) systems and government services, as well as their functional interconnection on a technical, semantic, as well as organisational level. To design a concrete ontology structure according to the purposes of the Access-eGov project and to fill it with data properly, three basic resources were identified, namely:

- a conceptual model provided by a selected semantic framework,

- $\quad$ existing and available ontology resources, and

- $\quad$ formalized requirements collected systematically from user partners of the project.

In the following paragraphs, we will describe each of these resources and the consequent process of ontology design in more detail.

\subsection{Access-eGov Ontologies}

After a detailed survey and analysis of existing and most used approaches (RDF-S, WSDL-S, WSMO, and OWL-S for ontologies; BPEL4WS for modelling web services in a business process interaction, etc. - see [2] for more details), it was decided to apply WSMO (Site 3) as a basic conceptual framework and implementation platform. The WSMO framework provides a consistent conceptual model for the semantic description of web services, with the inclusion of mediators and the distinction between goals and capabilities. It also provides the WSMX execution environment, the WSML language specification for ontology formalisation, as well as the WSMO Studio visual development environment. In addition, the WSMO conceptual model fits best the proposed architecture and functionality of the Access-eGov system [2], [15].

However, for modelling the government services the WSMO conceptual model had to be extended [21]. Based on the life event approach [10], two new top-level WSMO elements were added:

- The Life Event element as a formal model of users' needs, consisting of multiple goals and services organised into a generic scenario and expressed by an orchestration construction consisting of workflow, control-flow and data-flow sequences.

- $\quad$ The Service element as a generalisation of the Web service concept, already provided by WSMO. This extension allows the description of both electronic and traditional government services by means of a service profile, containing functional and non-functional properties, capabilities, and interfaces.

In addition to that, the process model has been modified, since the current WSMO specification provides a process model based on abstract state machines and is not structured in the way suitable for interaction with human actors as it is required for eGovernment applications. Therefore a workflow-based extension to the WSMO specification has been designed and implemented. The extended process model used within Access eGov is based on the workflow CASheW-s model [17]. The state signature is reused from the WSMO specification and replaces the transition rules with the workflow constructs. The shared ontology state signature allows reusing the grounding of input and output concepts to communication protocols via WSDL for invocation of web services. The workflow model consists of activity nodes connected with the control-flow or data-flow links. These nodes can be divided into atomic nodes (Send, Receive, AchieveGoal and InvokeService) and control nodes (Decision, Fork and Join).

Together with technologies for modelling, semantic models for the Access-eGov pilot applications had to be prepared. An Access-eGov ontology structure resulted from our survey of the worldwide available ontology resources. Using already existing ontologies assures a consistency with the widely accepted standards and avoids unnecessary double work. About 25 ontology resources and standards were analysed [3], and the following ones were finally selected for reuse: Dublin Core (Site 4), SKOS (Site 5), vCard (Site 6), SemanticGov, Terregov (Site 7), OntoGov, ontologies from WSMO (Site 8) and Protege (Site 9). 
In addition to technology and ontologies, requirements and use case information were collected from the Access eGov user partners in a systematic way. This information helped to produce sample ontology models of life events, sub-goals, and provided services for the pilot applications to be carried out within the project (within the AccesseGov project three pilot applications were analysed: in Slovakia - getting a building permit, in Poland - establishing a company, and in Germany - getting married scenario). The requirement-driven approach [3], [11], a method originally designed and developed within the Access-eGov project by one of the project partners (the German University of Cairo), was used as a main resource for ontology creation. This 7-step procedure starts with the identification of the user's information need for a particular case and continues with the analysis and the creation of more formal representations as controlled vocabularies and ontology-like networked structures of concepts and relations (Figure 1).

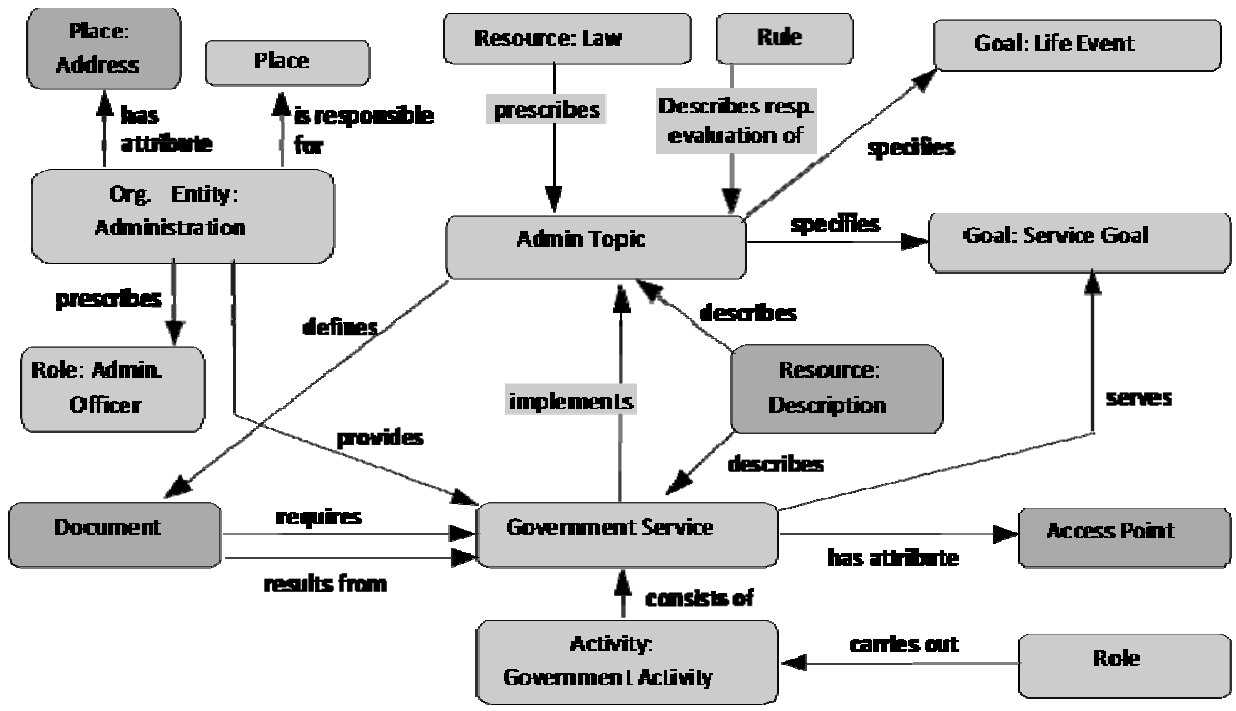

Figure 1: Ontology-like structure of identified terms (concepts) and their relations

At the end of this process, a fully formalised ontology expressed in WSML language was produced, containing all the semantics of life events, goals, services, and workflow structures. For example, the ontology fragment in (Figure 2) presents the WSML formalisation of the life event for "Getting married" (expressed as a complex goal) by means of the orchestration interface [18]. By interpreting this formal description, first a set of answers to pre-defined questions (Q1) needs to be provided by the user. Then other sub-goals (ApplyForMarriageGoal, etc.) need to be achieved in a proper order. Transitions in the controlFlow part express that all the nodes are executed in a sequence. The dataFlow part specifies that the variable from the first node (n1_1, the batch of questions) is equivalent to the variable from the decision node (n1_2).

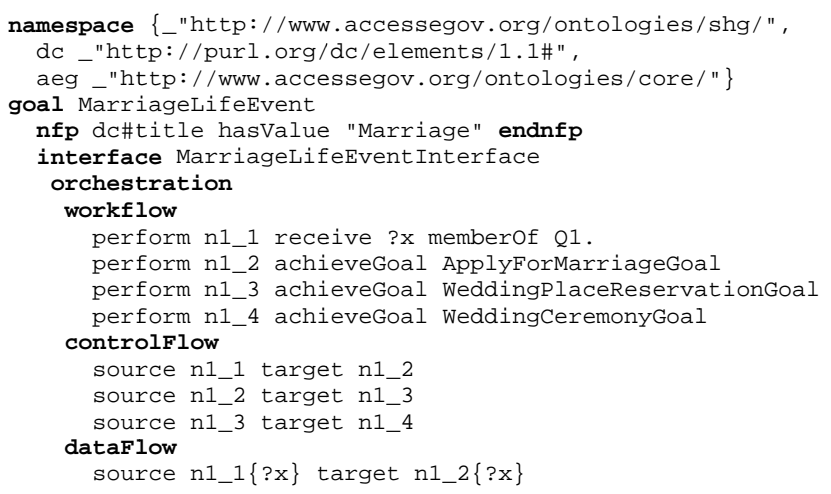

Figure 2: Fragment of the ontology in WSML notation

The whole process of designing and creating the ontologies, based on the requirement-driven approach, as it was carried out within the Access-eGov project for all the pilot applications, is described in detail in [3]. As a result of the 7-step procedure, the following ontologies were created and formalised by WSML language [13]:

- The Access-eGov Core Ontology containing definitions of basic elements (concepts, attributes, relations) that are shared among the pilot applications and used for the annotation of atomic services. The Core ontology was extended for the German field test, due to complex structure of spatial responsibilities (see description of the pilot applications in the next section). 
- The Life-Events Ontology containing conceptual descriptions of life events, complex goals (also referenced as generic scenarios), and elementary sub-goals for the pilots. Separate Life-Events ontologies were produced for each pilot application.

- Domain ontologies, providing domain-specific information for the pilots. The ontologies are fully localized (concepts have labels in several languages - in this case the labels are in English, German, Polish, and Slovak language) and include concepts for the description of forms, documents, certificates, location constraints, fees, questions, notification messages, etc. that are necessary to model the inputs and outputs of the provided government services. Separate domain ontologies were produced for each of the pilots.

From the side of the Access-eGov system, these ontologies can be seen as an interface between the technical infrastructure design and the pilot applications. They provide a specification of the inner data structure for the system components responsible for discovery, composition, mediation, and execution of services [2], [15].

\subsection{The Access-eGov System}

The Access-eGov system architecture is depicted in (Figure 3). The system consists of four main functional modules [8]:

- The data repository with Access-eGov resource ontology, a persistent data repository and a knowledge base that contains WSML representations of the life events and goals. In addition, it contains generic service concepts and service templates that enable the service annotation, as well as instances of already annotated services.

- The Access-eGov core components module, which includes the inner business logic of the system. The components are responsible for the decomposition of a given life event or goal into sub-goals, for the orchestration, composition, and mediation of the sub-goals within a workflow thread, for the semantic matching and discovery of the services for a given goal, as well as for the execution of the retrieved and resolved services.

- The Annotation Tool (AT) for the semantic description (i.e. annotation) of the services that are to be integrated by the Access-eGov system. The web-based interface allows information providers to specify the non-functional properties for various service types, including traditional face-to-face services (in this case, the service is described by an explanatory HTML text that is presented to citizens), electronic, and web services. The capability interfaces, required inputs and provided outputs and related workflow sequences are determined by a service template used during the annotation. The resulting WSML representations of the annotated service instances are stored in the resource ontology.

- The Personal Assistant Client (PAC) - a tool that enables users to browse and navigate through the life event and corresponding sub-goals. This web-based tool is implemented as a kind of wizard that allows personalising and customising the thread of sub-goals by answering a set of customisation questions, which can be defined in a process model of the semantic representation of the corresponding life events and subgoals.

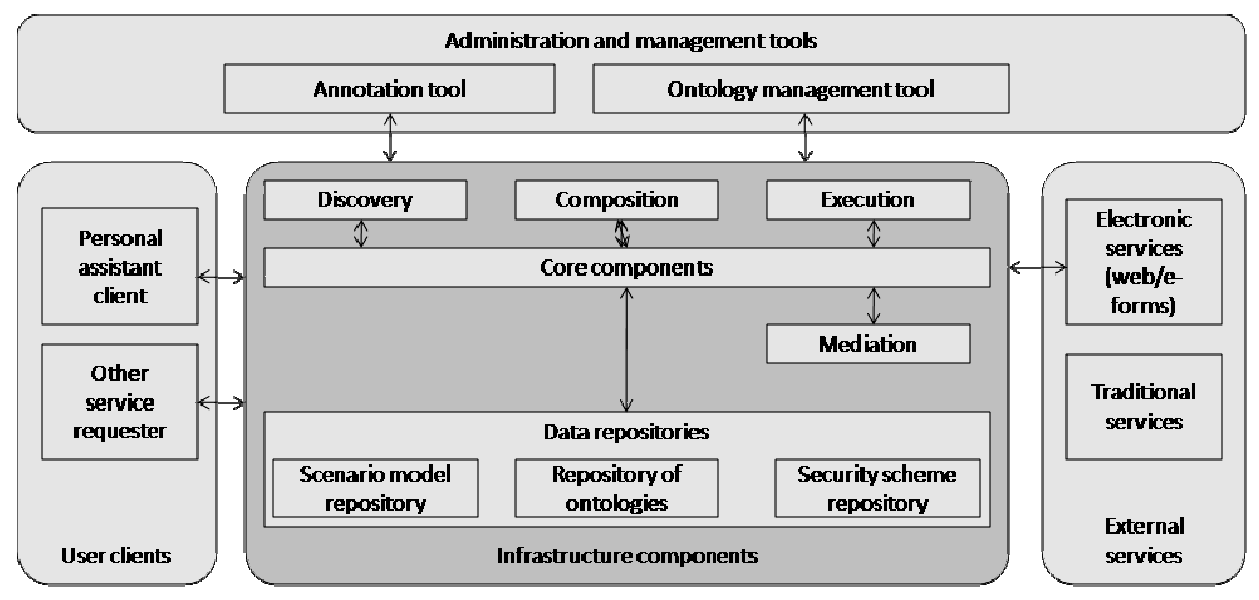

Figure 3: Access-eGov architecture

Before the system can be used, a knowledge engineer uses the Ontology management tool - WSMO Studio (Site 10) to create the resource ontology and customise it according to a given application case. The steps of the requirementdriven approach [3] can be employed to specify the life events and goals, as well as the services and service types 
(templates). The structure of life events and goals is then automatically populated to the PAC to be presented to the citizen or business user. However, the services that should correspond to particular goals need to be created separately, by means of semantic annotation by eGovernment service providers. For that step the AT is used. The structure of generic services and service templates, created in the resource ontology, is automatically populated to the AT. An annotator then uses the AT to semantically describe the services, i.e. to specify concrete values for particular non-functional properties, defined by the used service template. A WSML representation of the annotated services is created automatically and is uploaded into the resource ontology as a set of service instances. These service instances may contain a reference to an external web service or to existing web content (i.e. a portion of a web page). This reference is specified as a non-functional property of the service. After uploading the service instance to the ontology, the reference is evaluated, the external resource is validated, invoked, and the returning data is set as a default value for the service instance.

A citizen or a business uses the Personal Assistant Client (called PAC) to browse the life events and goals. Some of the goals may require an additional input that specifies the citizen's exact needs - to that end the citizen provides answers to customisation questions. The core system evaluates the answers obtained from the citizen for a given goal and dynamically creates a new thread of sub-goals, which is then returned back to the PAC. The process model of the goal is modified by the provided answers and its evaluation includes the procedures as service discovery, composition, orchestration, mediation, and execution. The core system communicates with the ontology to decompose a complex goal to sub-goals and to orchestrate, mediate, and compose the sub-goals into a workflow thread. For atomic goals which cannot be decomposed to sub-goals, the semantic matching procedure is used to discover and dynamically resolve a set of proper services. The core system then transforms the resolved services, according to their type, to an executable form and invokes the referenced external e-Gov services. Input values for the external services are populated from the input provided by users and/or calculated during the evaluation of the goal's process model. The output values provided by the invoked external services are returned to the process model, which is then modified accordingly and is presented to the citizen or to the business in the PAC.

\subsection{The Annotation Tool}

The ontologies provide a framework for semantic annotation of government services. The semantic annotation can be defined as a formal description of provided services by means of ontology elements, including a composition of the services into more complex goals and life events. This is a key issue, which enables integration and interoperation of services on a semantic basis. The semantic annotation and maintenance of semantically described services is the task of PA employees - they should use the concepts from the ontologies (mostly from the domain ontologies) to specify functional properties, i.e. required inputs and outputs, as well as non-functional properties, i.e. descriptions and preconditions, as parameters of the services. However, since the semantic annotation of services has to be formally expressed in WSML language, a software tool supporting the annotation process in a user-friendly way is needed. The above mentioned WSMO Studio can be, in principle, used as such a tool, but it is dedicated mostly for WSMO/WSML specialists and is too complicated for standard PA employees with very limited or no knowledge of semantic technologies. For this reason, a specialised Annotation Tool [3] (Figure 4) has been developed in the project, which is easy-to-use and requires only standard PC skills.

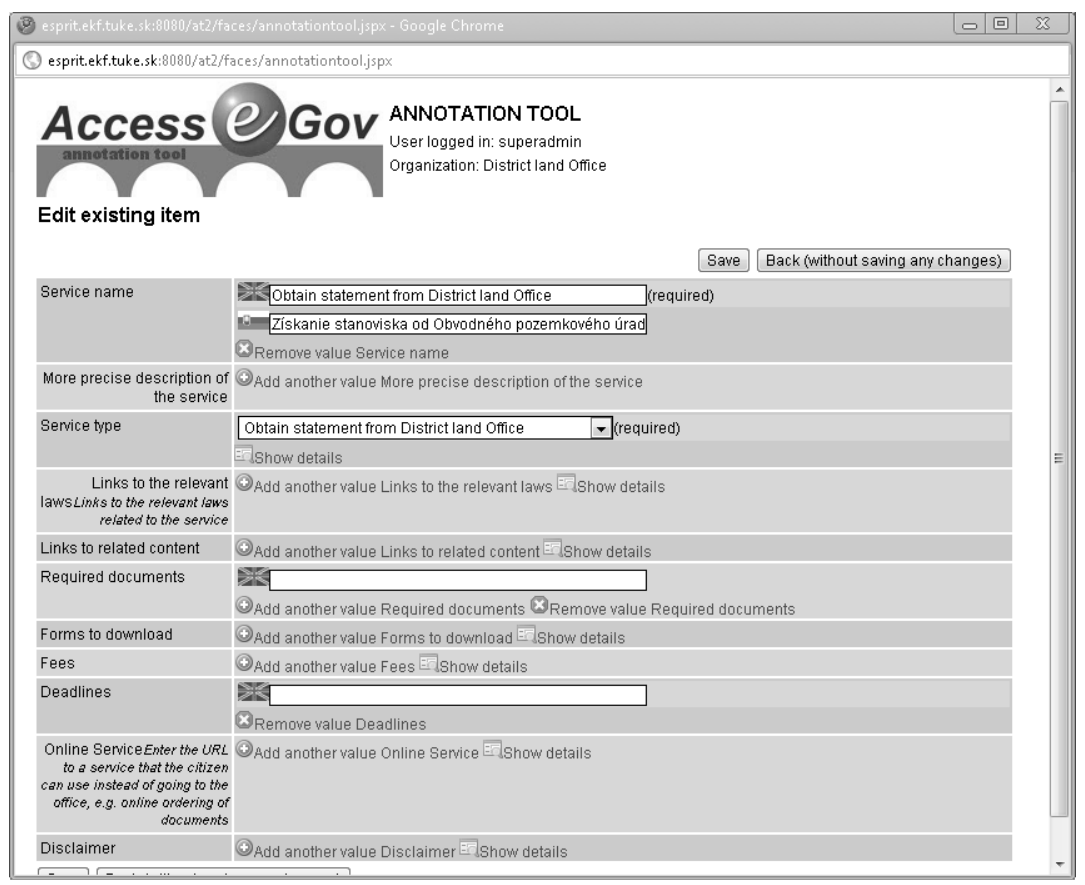

Figure 4: Annotation tool, user interface, annotation of a service 
The Annotation Tool was implemented as a standard web application, using the extended WSMO object model and JSF technology. The tool provides to PA officers a set of forms for the specification of preconditions and nonfunctional properties as parameters of the government services. A template mechanism was implemented to ease the maintenance of predefined workflow sequences for the annotated services. A simple user access control and multilingual support, on both interface and data level, is also included in the Annotation tool. In addition, a simple "content grabber" functionality enables to link particular field in the form (i.e. the value of a service parameter, e.g. service hours of an office) with an element on an existing web site of the public administration. This solution allows to annotate the external web pages and semantically integrate their content into a unified eGovernment application.

\subsection{The Personal Assistant Client}

On the side of citizens, the Personal Assistant Client (Figure 5) was developed as a tool that provides browsing, discovery, and execution of proper government services for citizens and businesses according to a specified life event or goal.

Again, the Personal Assistant Client was implemented as a web application using JSF technology. Layout, structure, and ordering of tabs in the interface are dynamically created from the annotated services and are customised based on the conditions of the given user. After selecting a life event, the corresponding navigation structure of sub-goals and services is displayed for users in the form of textual information, a hyperlink, a field for inserting a specified input value, or an interface for the invocation of a web service. Users can browse sub-goals and provide their answers when customisation input is requested. Then the system automatically resolves the sub-goals and navigates the user to a new set of sub-goals and services inferred from the conceptual model. The Access-eGov system can also directly invoke electronic services provided via a standardised web service interface. Finally, the user obtains all available information on the life event customised to his/her case, and has also the possibility to execute the actions required for particular services needed for the accomplishment of the life event.

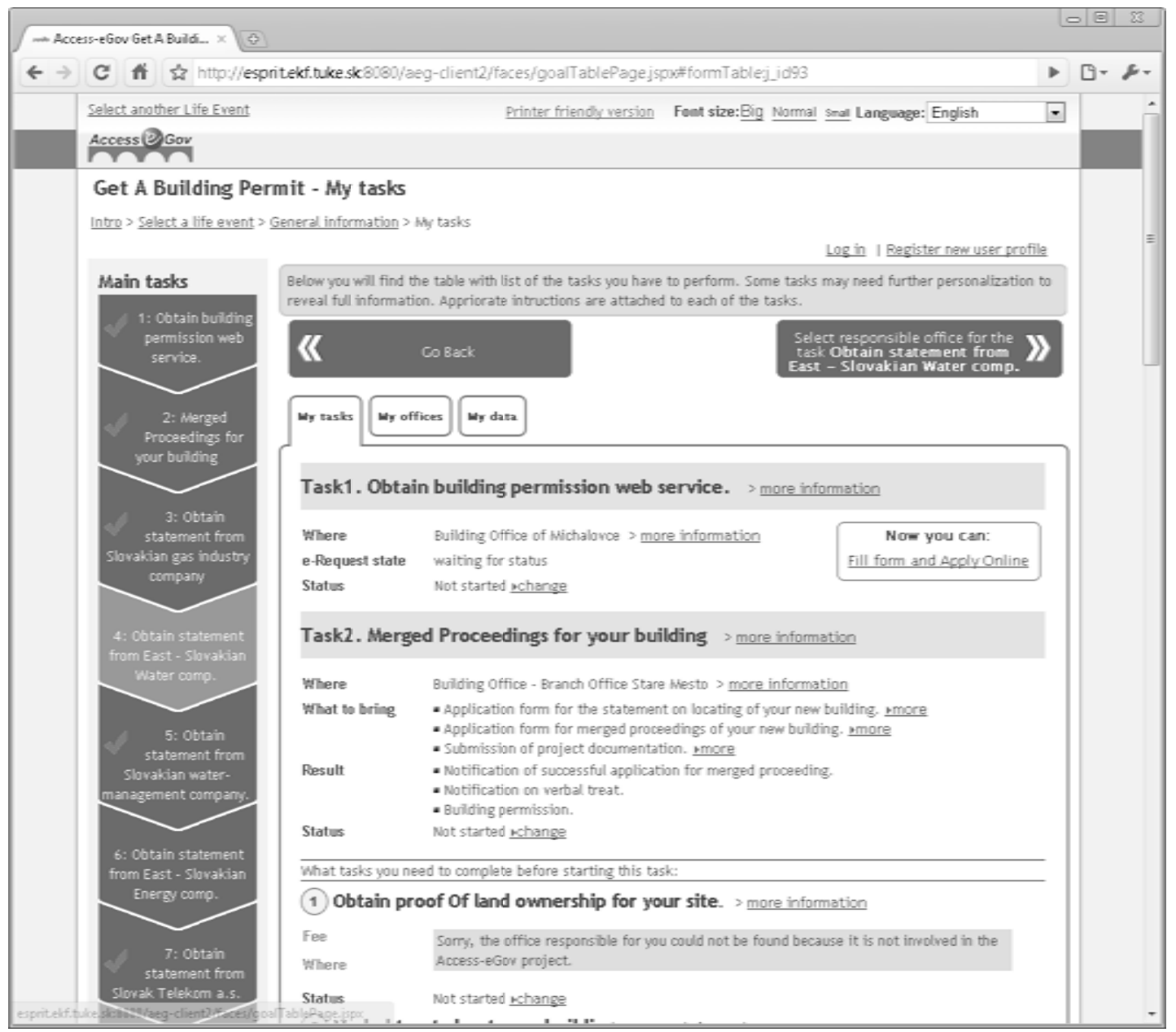

Figure 5: Personal assistant client, user interface, browsing the Build a House life event

In the following section, the Access-eGov pilot applications are described. Focus is put on testing the tools providing enhanced service interfaces as well as on the retrospective evaluation of the ontology design approach. 


\section{Pilot Applications}

As an initial test of the developed SW tools, a lab test took place in Egypt, carried out by the German University in Cairo, to ensure the functionality and technical capabilities of the whole system. After the tools were ready for installation and usage by user partners, a field test in Germany and two pilot applications in Slovakia and Poland were carried out to test the applied approach within real settings in the public administration.

\subsection{Lab Test in Egypt}

The lab test in Egypt was designed to test the perspective of information consumers through the use of the Personal Assistant Client. Testers were recruited among the university students and were asked to perform and document a series of tasks. The documented results were later evaluated with regard to the completeness and correctness of the received information.

The tasks were designed using the scenario and ontology from the German field test and were intended to bring the test as close to real-life situations as possible. 14 testers performed three different tasks each (42 test cases in total) over a period of three days. The tests were conducted as supervised lab tests with the focus on real-life tasks. Each task took around 90 minutes to complete including organisational overhead. One task was focused on those aspects of the Personal Assistant Client that deliver non-personalised information, while other two tasks focused on customisation by providing personalised information.

\subsection{German Field Test: “Getting Married"}

The Ministry of Finance of Schleswig-Holstein in Germany carried out the German field test. It was focused on the life event "Marriage" and related procedures. The main aim of this field test was to test the integration of different web resources containing service information and making them accessible via a single platform but still leaving the data and its maintenance in the municipalities' legacy systems. The process of semantic annotation of existing heterogeneous web resources should make the meaning of the distributed information explicit and should allow integration and interoperability of this annotated data. In the "Marriage" life event, usually different registry offices have to be contacted by a citizen to obtain the documents necessary for the marriage. Services of the registry offices in Schleswig-Holstein were thus annotated on the basis of a common conceptual model and made accessible via the Access-eGov platform.

The registry offices of eleven municipalities from Schleswig-Holstein have been involved in this field test. Two main phases in the trial can be distinguished: First, the administration officers created service annotations using the Annotation Tool. After that, citizens were asked to use the Personal Assistant Client to retrieve information about these services. In the first phase (September - December 2007), different registry offices described their government services, following the steps of the requirement-driven approach described above (to facilitate this, a short training to the involved public servants was delivered). The life events and domain ontologies were produced and the Annotation Tool was updated according to the underlying conceptual model.

In the second phase of the field test (January - February 2008), the Personal Assistant Client providing support for a "Marriage" life event was tested and evaluated by the involved municipalities and by the public. Quite extensive dissemination activities were carried out and an online questionnaire was used for the evaluation of the SW tools used.

The results of the evaluation of all the pilot applications are presented in section 3.5 below. A more detailed description of the German field test, including the process of conceptual model development and specific evaluation of both methodology and tools is provided in [3].

\subsection{Slovak Pilot: "Obtaining a Building Permission"}

The Kosice self-governing region and the municipality of Michalovce carried out the Slovak pilot. It focused on supporting citizens during the process of asking for a building permit, including complex services related to land-use planning and approval proceedings. The objective of this pilot was to make the whole process easier and more transparent for citizens, to provide all relevant information about the necessary services in a comprehensive and user-friendly way, and finally to improve the service from the citizen's point of view.

At the beginning, a set of four scenarios (i.e. scenarios for land-use proceedings, building proceedings, merged procedure of land-use and building proceedings, and final approval proceedings) for the life event of obtaining a building permission was formulated and, using the requirement-driven approach, the corresponding ontologies were produced. An installation of the Annotation Tool connected to this conceptual model was created, which was then used for extensive testing, training of public servants, and annotation of the services. The Personal Assistant Client was connected to the conceptual model containing the annotated life events and services, and the interface of the tool in Slovak as well as in the English language was provided. 


\subsection{Polish Pilot: "Establishing an Enterprise"}

The Polish pilot took place in the Silesian region and was performed by the Gliwice City Hall (GCH). The user scenario of the example process was focused on the life event "Establishment of an enterprise" and involved four main user goals: registration in the local government, registration in the statistical office, registration in the tax office and registration in the social insurance agency. The objective of the Polish pilot application was to provide a single entry point where users (citizens and entrepreneurs) can obtain relevant information and are properly navigated by the system within the whole complex process.

The preparation of the pilot was similar to the Slovak pilot. The scenarios prepared contained a detail description of all the steps in the process, as e.g. registration into various institutions, possible paths of registration dependent on the individual user's case, all required documents and forms as well as information, which must be collected from the user to construct the path relevant to the user's needs. According to the scenarios, the relevant services (both electronic and traditional services) were identified and information on service providers in the Gliwice area was collected. Using the requirement-driven approach, the data was formalised into the underlying conceptual model.

The Gliwice City Hall is an institution of first contact for citizens interested in establishing an enterprise and often plays the role of information provider and a proxy between citizens and the statistical or tax office. GCH was thus able to formulate the user requirements as the most frequent requests of citizens. According to the defined user requirements and identified types of available services, a schema of a "dialogue" with the user was prepared. All of the questions were formulated as Yes/No questions or questions with a predefined set of answers. Depending on previously chosen answers, further questions are asked and the requirements and relevant forms are introduced to the user. Installations of the Annotation Tool and Personal Assistant Client were created and connected with the produced conceptual model. The interface was translated into Polish language. The testing carried out in a realistic setting was similar to the other pilots. The public tested the Personal Assistant Client in February 2008. There were three groups of testers: domain experts ( $\mathrm{GCH}$ civil servants involved in process preparations), IT experts (Polish project members) and "the public" (common citizens, people not involved in the Access-eGov project).

\subsection{Evaluation of the Pilot Applications}

The evaluation methodology considered overarching categories how to describe the existing situation in detail, the expected improvements from the user point of view, and how to set up measurements as well as an evaluation strategy. Expected improvements (thanks to the use of the Access-eGov system) from the user point of view were identified in: a) the informational output, as well as b) in the process itself. Improvement evaluation therefore built on criteria elaborated in relation to: 1) information quality, 2) process automation, rationalization and reengineering, as well as 3 ) other issues such as usability of interfaces, security and trust. The evaluation process is fully described in [12].

Practically, the evaluation consisted of a user evaluation of the client-side tools (the Annotation Tool and Personal Assistant Client) as well as a technical evaluation of the Access-eGov system in general. The technical evaluation was run during the software development and was based on a standard multilevel technical and source code testing. The user evaluation took place after both trials of the pilot applications. Within each of the three pilot applications, two trials were carried out. Results from the first trial were transformed into the user requirements for the second trial. The evaluation of the second trial was then used to finalize the project results (i.e. SW tools, methodology etc.). The Annotation Tool served its purpose well during the testing. The feedback from the tests showed that the tool was relatively easy to use and was successfully used even by non-trained users (annotation authors) who had only a short user manual at their disposal. A few annotators found the process of semantic annotation "not so easy", because of non-intuitive use of the Annotation Tool and a lack of understanding concerning which information had to be filled in. Also a mixture of user roles and respective rights caused some difficulties. Most of these issues were fixed after the trial. Generally, the annotators managed to annotate all services and found the Annotation Tool useful and efficient. Most of the criticism of users during the first trials was towards the user interface, i.e. the usability of the PAC. It was not surprising, since this tool is a front-end and "the most visible" component of the platform. It was the reason why the PAC's user interface was completely redesigned and enhanced according to the feedback obtained from the users. The updated PAC conforms to the "single A" level of the W3C WCAG eAccessibility criteria (Site 11). General results of the online questionnaire (Figure 6) show that most of the assessed categories were on the positive side of the scale in both trials and improved after the first trial. Only two categories were assessed worse in the second trial than in the first trial. The largest improvement was in the identification of the source of published information. The second largest improvement was related to the information completeness, which proved a sufficient amount of precise and complete information on the Access-eGov website. Overall, the application was positively accepted both by the information providers (governmental offices, service providers) and information consumers (citizens, small businesses). 


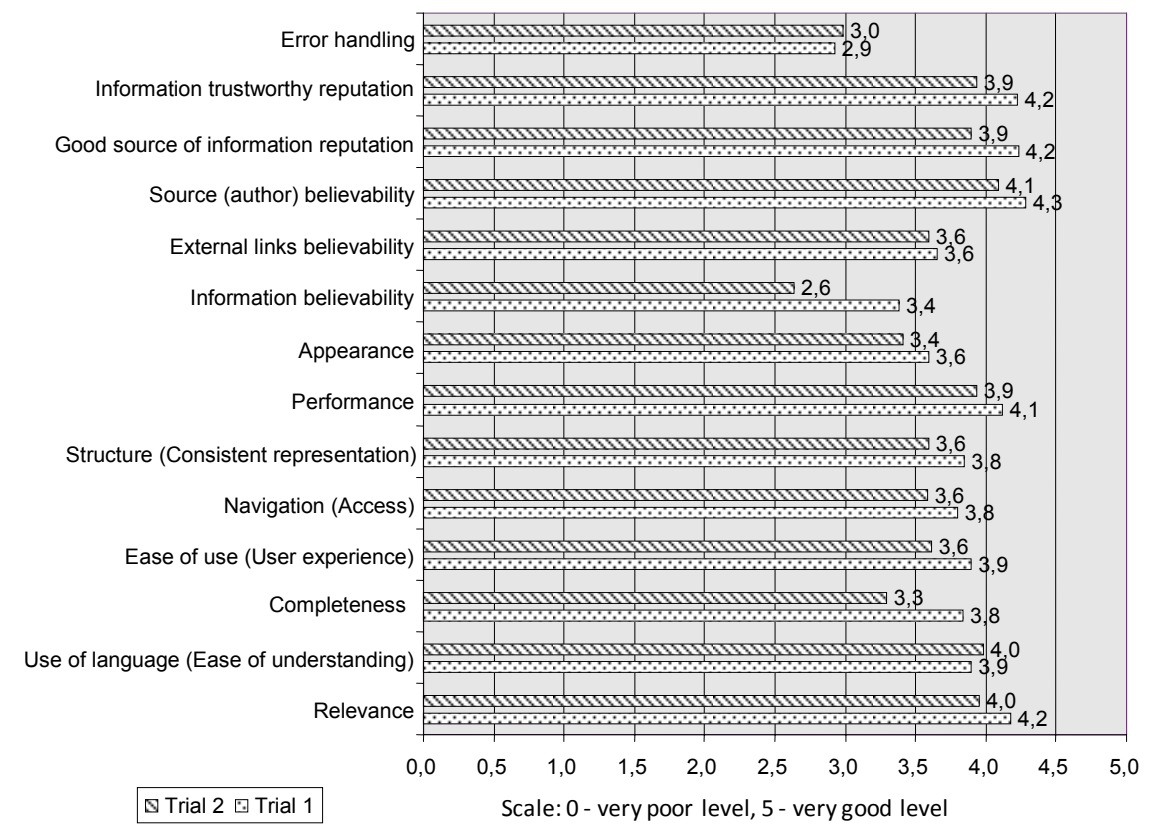

Figure 6: Evaluation test results of the trial

\section{Conclusion and Lessons Learnt}

It was very important to involve the user partners (public administrations) into development and testing of the system in a realistic environment. A balanced cooperation between technology developers and public administration authorities is regarded essential, since public administration organizations are needed to provide domain knowledge, to annotate services as well as to update the annotated information. Their support and commitment to the vision of citizen-centric service delivery is of paramount importance because of the vibrant changes in this field of application, e.g. as software in the public administration sector is subject to frequent changes in legal regulations.

Transforming data from simple websites into semantically annotated data required in some cases a significant amount of annotation effort. Maybe in the future, when semantic technologies will be used by a variety of tools that can make use of the same annotated data, the real advantages of this technology will come into full effect and justify the additional annotation effort. Creating semantically enriched service descriptions from websites that are built from well structured databases or via a web service interface proved to be faster and effective already at the present stage of development.

Making services accessible by using semantic technologies also meant to agree on the semantics of public administration services. This process is not so much about technologies but mainly about communication and cooperation between different administrations with different views on the concepts that have to be described. While the project was running, parallel efforts on national levels were made to agree on a unique system for typing services as well as for describing other concepts from the area of public administration. The results of these efforts will facilitate the employment of semantic technologies on a national and international level in the future. The AccesseGov project has shown, via its pilot applications, how the use of such standards can be exploited.

Evaluation in several different real settings has proven feasibility of the idea presented in the paper. Citizens highly appreciate support in identifying services relevant to their life situations and combining these services in a contextdependent way to produce customised scenarios, which are able to cope with various situations the citizens are facing. On the other hand, this idea is also quite attractive for public administrations providing services, since the services are being integrated in a 'front-office' manner - i.e. without interfering with existing administrations and/or back-office integration. Since this approach enables to combine traditional (face-to-face) paper-based services with electronic services, it could serve as a vehicle for public administrations to transform their processes in a step-bystep manner, while imposing only low entry barriers - by simply integrating services as they are currently provided and subsequently upgrading traditional services to electronic ones.

The trial applications of the project were only a proof of the concept within a small scope of potential users. Lack of really used electronic services in e-government was the biggest treat to overcome during the project. As long as there will be no relevant amount of really accessible electronic services, the Access-eGov solution will serve only half of its potential. Our trials proved that using semantic web services has a potential in enabling the interoperability of 
governmental (and possibly also non-governmental) services within complex citizen and business life situations. The software products of the project are available as open source free of charge software. Private companies, which were part of the consortium are ready to provide a support in customization of the solution for anyone interested in the product. However, the biggest challenge remains the task of closing the gap between the semantic interoperability, for which the proposed solution was developed, and the organizational interoperability, which means a closer relation between organizational and technical changes in provisioning of services toward the interoperable electronic government.

\section{Acknowledgments}

The Access-eGov project was co-funded by the European Commission within the contract No. FP6-2004-27020.

\section{Websites List}

Site 1: EC Projects and activities, IST eGovernment projects, Sixth Framework Programme Call 4 http://ec.europa.eu/information society/activities/egovernment/projects/index en.htm

Site 2: Access eGov project site www.access-egov.org

Site 3: Web Service Modelling Ontology working group www.wsmo.org

Site 4: The Dublin Core ${ }^{\circledR}$ Metadata Initiative http://dublincore.org

Site 5: SKOS Core Vocabulary Specification http://www.w3.org/TR/2005/WD-swbp-skos-core-spec-20051102

Site 6: Representing vCard Objects in RDF http://www.w3.org/2006/vcard/

Site 7: Terregov - Impact of eGovernment on Territorial Government Service, project webpage http://www.terregov.eupm.net

Site 8: WSMO Ontologies

http://www.wsmo.org/WSMO ontologies.html

Site 9: Protege Ontologies Library

http://protege.cim3.net/cgi-bin/wiki.pl?ProtegeOntologiesLibrary

Site 10: WSMO Studio - an open source Semantic Web Service and Semantic Business Process modelling environment www.wsmostudio.org

Site 11: Web Content Accessibility Guidelines www.w3.org/TR/WCAG20/

\section{References}

[1] A. Abecker, A. Sheth, G. Mentzas, and L. Stojanovich, Technical Report SS-06-06, in Proceedings of AAAI Spring Symposium Semantic Web Meets eGovernment, Stanford University, Menlo Park, CA, March 27-29, 2006.

[2] P. Bednar, S. Duerbeck, J. Hreno, M. Mach, L. Ryfa, and R. Schillinger, (2006, February) Access-eGov Platform Architecture. Deliverable D3.1, Access-eGov Project. [Online]. Available: http://www.access-egov.org/acegov/ uploadedFiles/webfiles/cffile $4 \quad 3 \quad 07 \quad 3 \quad 25 \quad 17$ PM.pdf.

[3] P. Bednár, K. Furdík, M. Kleimann, R. Klischewski, M. Skokan, and S. Ukena, Semantic Integration of eGovernment Services in Schleswig-Holstein, Electronic Government, in Lecture Notes in Computer Science, vol. 5184/2008, 2008, pp. 315-327.

[4] COM. (2002, May). eEurope 2005: An information society for all. [Online]. 263 final of 28 May 2002. Brussels. Available: http://ec.europa.eu/information society/eeurope/2002/news library/documents/eeurope2005/ eeurope2005 en.pdf.

[5] COM. (2005, June). i2010 - A European Information Society for growth and employment. [Online]. Available: http://eur-lex.europa.eu/LexUriServ/LexUriServ.do?uri=COM:2005:0229:FIN:EN:PDF 
[6] COM. (2006, February). Interoperability for Pan-European eGovernment Services. [Online]. Available: http://eurlex.europa.eu/LexUriServ/LexUriServ.do?uri=COM:2006:0045:FIN:EN:PDF.

[7] K. Furdík, J. Hreňo, and T. Sabol, Conceptualisation and Semantic Annotation of eGovernment Services in WSMO, in Proceedings of Znalosti (Knowledge), STU, Bratislava, Slovakia, 2008, pp. 66-77.

[8] K. Furdík, R. Klischewski, M. Paralič, T. Sabol, and M. Skokan, E-Government Service Integration and Provision Using Semantic Technologies, in Proceedings of Ongoing Research, General Development Issues and Projects of EGOV 09, 8th International Conference, Trauner Verlag, Linz, Austria, 2009, pp. 273-280.

[9] L. Giantsiou, A. Simov, N. Loutas, V. Peristeras, and K. Tarabanis, The WSMO-PA Service Editor, in Proceedings of the IEEE international Conference on Semantic Computing, Washington, DC, pp. 492-493, August 4-7, 2008.

[10] A. Gugliotta, L. Cabral, J. Domingue, Knowledge Modelling for Integrating E-Government Applications and Semantic Web Services, in Proceedings AAAI Spring Symposium Series Semantic Web meets E-Government, California, USA, 2006, pp. 21-32.

[11] R. Klischewski, S. Ukena, Designing semantic e-Government services driven by user requirements, in Proceedings of ongoing research, project contributions and workshops, 6th International EGOV Conference, Trauner Verlag, Linz, Austria, 2007, pp. 133-140.

[12] R. Klischewski, S. Ukena, Trial evaluation strategy. Deliverable D8.1, Access-eGov Project, April 2007. [Online]. Available: http://www.access-egov.org/acegov/uploadedFiles/webfiles/cffile 2200853546 PM.pdf.

[13] R. Klischewski, S. Ukena, K. Furdik, A. Marciniak, J. Hreno, M. Skokan, Public administration resource ontologies. Deliverable D7.1, Access-eGov Project, November 2007. [Online]. Available: http://www.accessegov.org/acegov/uploadedFiles/webfiles/cffile 2200855043 PM.zip.

[14] A. Leben and M. Vintar, Life-Event Approach: Comparison between Countries, in Electronic Government, Springer LNCS 2739, pp. 434-437, 2003.

[15] M. Mach, P. Bednár, J. Hreňo, Execution and Composition of Government Services, in Proceedings of the 1st International Conference on Methodologies, Technologies and Tools Enabling e-Government, Camerino, Italy, September 27-28, 2007, pp. 139-153.

[16] M. Mach, T. Sabol, J. Paralič, Integration of eGov services: back-office versus front-office integration, in Proceedings of the Workshop Semantic Web for eGovernment, a Workshop at the 3rd European Semantic Web Conference, ESCW 2006, Budva, Serbia - Monte Negro, 2006, pp. 48-52.

[17] B. Norton and C. Pedrinaci, 3-Level Service Composition and Cashew, A Model for Orchestration and Choreography, in Semantic Web Services, Springer LNCS 4277, pp. 58-67, 2006.

[18] J. Scholl, R. Klischewski, E-Government Integration and Interoperability: Framing the Research Agenda, International Journal of Public Administration, vol. 30, no. 8-9, pp. 889-920, 2007.

[19] M. Skokan, P. Bednár, Semantic orchestration of services in eGovernment, in Proceedings of Znalosti (Knowledge) 2008. STU, Bratislava, Slovakia, 2008, pp. 215-223.

[20] E. Tambouris, Introducing the need for a domain model in Public Service Provision (PSP) eGovernment Systems, in Proceedings of 3rd International Conference on Digital Information Management ICDIM, 2008, pp.794-799.

[21] X. Wang, S. Goudos, V. Peristeras, T. Vitvar, A. Mocan, K. Tarabanis, WSMO-PA - Formal Specification of Public Administration Service Model on Semantic Web Service Ontology, in Proceedings of the 40th Hawaii International Conference on System Sciences, IEEE Computer Society, Hawaii, USA, 2007, pp. 96-106. 